\title{
Toward a Model of Polymorphism Comprehension
}

\author{
Joshua B. Gross \\ Department of Computer Science \\ CSU Monterey Bay \\ Seaside, CA, USA \\ jgross@csumb.edu
}

\author{
Gabriel S. Oliveira \\ Department of Computer Science \\ North Carolina State University \\ Raleigh, NC, USA \\ gsilvad@ncsu.edu
}

\author{
Kevin Coogan \\ Department of Computer Science \\ Blackburn College \\ Carlinville, IL, USA \\ kevin.coogan@blackburn.edu
}

\begin{abstract}
Polymorphism is challenging for novice programmers because it is an emergent consequence of multiple language features. OO polymorphism is critical to flexible software design, but no model currently explains student comprehension. In this research, students implemented the Strategy pattern to improve their comprehension of polymorphism, then were assessed by professional developers in whiteboard interviews. From these data, the authors work toward deriving a model of novice comprehension of polymorphism.
\end{abstract}

\section{CCS CONCEPTS}

Social and professional topics $\rightarrow$ Computer science education

\section{KEYWORDS}

CS2, Object-oriented programming, Polymorphism, Design patterns, Whiteboard interviews

\section{INTRODUCTION AND RELATED WORK}

This research was motivated by students' inability to solve whiteboard interview problems involving polymorphism. Polymorphism is the most complex concept addressed in introductory $\mathrm{OO}$ programming courses. Unlike more primitive concepts, polymorphism requires correctly integrating several concepts that students find challenging to use even in isolation; even experienced CS teachers struggle to learn [1]. No current model explains stages of novice comprehension of polymorphism, and testing such knowledge on an exam is difficult at best.

\section{METHODS}

Students completed two programming assignments using polymorphism. The second was an interactive, animated gin card game, using a custom card game framework. Students built the logic to play a hand using Strategy, a design pattern that uses polymorphism to wrap calls to one of several classes, each of which implements different rules for a different stage of the game.

Permission to make digital or hard copies of part or all of this work for personal or classroom use is granted without fee provided that copies are not made or distributed for profit or commercial advantage and that copies bear this notice and the full citation on the first page. Copyrights for third-party components of this work must be honored. For all other uses, contact the Owner/Author.

SIGCSE '20, March 11-14, 2020, Portland, OR, USA

(C) 2020 Copyright is held by the owner/author(s)

ACM ISBN 978-1-4503-6793-6/20/03.

https://doi.org/10.1145/3328778.3372664
Students then completed a whiteboard interview [2] conducted by industry professionals, using a problem building on the card framework. Researchers identified 8 distinct polymorphic design milestones, ranging from isolating functionality in classes to polymorphic object substitution. Using closer analysis and a grounded codebook, researchers are working toward a three-level model of comprehension: structured software principles, OO principles, and $\mathrm{OO}$ polymorphism principles.

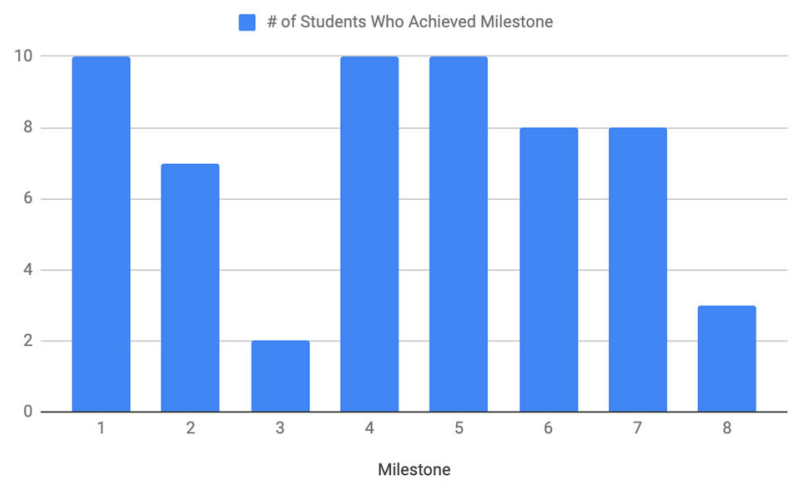

\section{FUTURE WORK}

The researchers are working to build appropriate support for the three-level model based on more in-depth analysis of current data, and from a second run of the course. One future goal is to not require a whiteboard interview to assess student comprehension.

\section{ACKNOWLEDGMENTS}

The authors are thankful for support from Sarah Heckman and the NSF-funded DEERS project. The authors also thank Joe Vest and his employees from Karmak for their work in conducting the whiteboard interviews, and Cordell Stocker for programming.

\section{REFERENCES}

[1] Liberman, N. et al. 2011. Difficulties in Learning Inheritance and Polymorphism. ACM Trans. Comput. Educ. 11, 1 (Feb. 2011), 4:1-4:23.

[2] Ford, D. et al. 2017. The Tech-Talk Balance: What Technical Interviewers Expect from Technical Candidates. 2017 IEEE/ACM 10th International Workshop on Cooperative and Human Aspects of Software Engineering (CHASE) (May 2017), 43-48. 